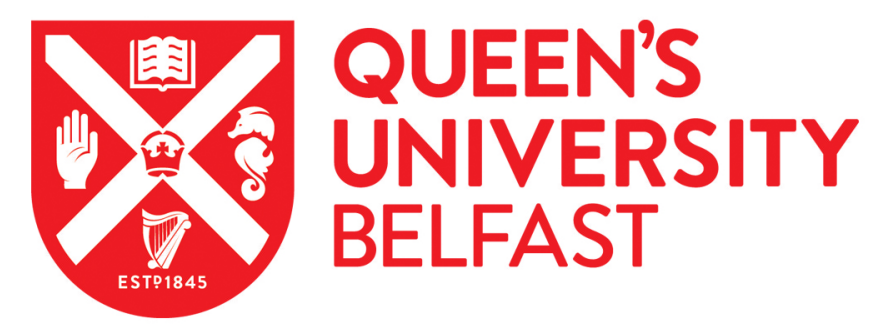

\title{
Identifying consumer-resource population dynamics using paleoecological data
}

Einarsson, Á., Hauptfleisch, U., Leavitt, P. R., \& Ives, A. R. (2016). Identifying consumer-resource population dynamics using paleoecological data. Ecology, 97(2), 361-371. https://doi.org/10.1890/15-0596.1

\author{
Published in: \\ Ecology
}

\section{Document Version:}

Peer reviewed version

Queen's University Belfast - Research Portal:

Link to publication record in Queen's University Belfast Research Portal

\section{Publisher rights}

Copyright 2016 Ecological Society of America. This work is made available online in accordance with the publisher's policies. Please refer to any applicable terms of use of the publisher.

\section{General rights}

Copyright for the publications made accessible via the Queen's University Belfast Research Portal is retained by the author(s) and / or other copyright owners and it is a condition of accessing these publications that users recognise and abide by the legal requirements associated with these rights.

Take down policy

The Research Portal is Queen's institutional repository that provides access to Queen's research output. Every effort has been made to ensure that content in the Research Portal does not infringe any person's rights, or applicable UK laws. If you discover content in the Research Portal that you believe breaches copyright or violates any law, please contact openaccess@qub.ac.uk. 
$6 \quad{ }^{1}$ Mývatn Research Station, IS-660 Mývatn, Iceland

$8 \quad{ }^{2}$ Institute of Life- and Environmental Sciences, Askja, Sturlugata 7, University of Iceland, IS-101

$9 \quad$ Reykjavík, Iceland

10

$11{ }^{3}$ Faculty of Earth Sciences, Askja, Sturlugata 7, University of Iceland, IS-101 Reykjavík, Iceland 12

$13{ }^{4}$ Department of Biology, University of Regina, Regina, SK, Canada S4S 0A2

14

$15{ }^{5}$ Department of Zoology, University of Wisconsin, Madison, WI 53706, USA

16

17

18 
20 Ecologists have long been fascinated by cyclic population fluctuations, because they suggest

21 strong interactions between exploiter and victim species. Nonetheless, even for populations

22 showing high-amplitude fluctuations, it is often hard to identify which species are the key drivers

23 of the dynamics, because data are generally only available for a single species. Here, we use a

24 paleoecological approach to investigate fluctuations in the midge population in Lake Mývatn,

25 Iceland, which ranges over several orders of magnitude in irregular, multi-generation cycles.

26 Previous circumstantial evidence points to consumer-resource interactions between midges and

27 their primary food, diatoms, as the cause of these high-amplitude fluctuations. Using a pair of

28 sediment cores from the lake, we reconstructed 26 years of dynamics of midges using egg

29 remains, and algal groups using diagnostic pigments. We analyzed these data using statistical

30 methods that account for both the autocorrelated nature of paleoecological data and measurement

31 error caused by the mixing of sediment layers. The analyses revealed a signature of consumer-

32 resource interactions in the fluctuations of midges and diatoms: diatom abundance (as inferred

33 from biomarker pigment diatoxanthin) increased when midge abundance was low, and midge

34 abundance (inferred from egg capsules) decreased when diatom abundance was low. Similar

35 patterns were not found for pigments characterizing the other dominant algal group in the lake

36 (cyanobacteria), subdominant algae (cryptophytes), or ubiquitous but chemically unstable

37 biomarkers of total algal abundance (chlorophyll-a); however, a significant but weaker pattern

38 was found for the chemically stable indicator of total algal populations ( $\beta$-carotene) to which

39 diatoms are the dominant contributor. These analyses provide the first paleoecological evaluation

40 of specific trophic interactions underlying high amplitude population fluctuations in lakes. 
42 Key words: fossil pigments; Lake Mývatn; Chironomidae; diatoms; population fluctuations;

43 consumer-resource dynamics; Iceland.

44 


\section{INTRODUCTION}

Cyclic population dynamics have generated one of the oldest and largest bodies of

47 literature in ecology, starting with the classic models of Lotka showing that population cycles can

48 be generated by predator-prey, or more generally, exploiter-victim interactions (Lotka 1925).

49 Population cycles have generated this interest because they are an easily observed signal of

50 strong interactions among species (Kendall et al. 1999). Despite the numerous population cycles

51 that have been documented, in many cases it is unclear what are the key species driving the

52 cycles. For the iconic snowshoe hare cycles, only extensive research over many decades led to

53 the generally accepted hypothesis that cycles are driven primarily by predation from lynx and

54 other specialist predators, with secondary importance attributed to interactions with the hare food

55 base (Krebs et al. 1995, Krebs 2011). At high latitudes, cycles of microtine rodent populations

56 are common, yet there is still debate over the relative importance of top-down interactions

57 between rodents and predators in driving the cycles (Stenseth 1999, Turchin and Hanski 2001).

58 For insects, numerous cyclic populations have been documented, especially among forest pests;

59 the majority are explained by interactions with predators or parasites, although the identities of

60 the predators or parasites are often just speculations (Myers 1988, Turchin 2003, Turchin et al.

612003 , Dwyer et al. 2004). Identifying the interactors who generate cycles between herbivores and

62 plants might be easier given the sedentary nature of plants, but with a few exceptions (Berryman

63 1976, Berryman et al. 1978), herbivore-plant cycles appear rare. Finally, although there is

64 considerable data on both zooplankton and phytoplankton in lakes, cyclic dynamics that are

65 sustained across multiple years (rather than the well-known annual clear-water period caused by

66 high consumption rates following spring turnover) are apparently rare (Murdoch et al. 1998),

67 despite the ability to find these cycles in the lab (McCauley et al. 1999, McCauley et al. 2008). 
68 Thus, understanding most of the population cycles observed in nature is hampered by the absence 69 of data on a candidate partner species.

Almost 40 years of ecological monitoring in Lake Mývatn, Iceland, have revealed highamplitude fluctuations in the abundance of midges (chironomids) that span several orders of magnitude (Einarsson et al. 2002, Einarsson and Gulati 2004, Gardarsson et al. 2004). Because midges make up more than $90 \%$ of the secondary production of the lake benthos (1972-1974,

74 Lindegaard and Jónasson 1979), the fluctuations generate huge changes to the trophic structure of the lake and drive fluctuations throughout the lake food web (Einarsson and Gulati 2004). The midge fluctuations are cyclic, in the sense that they show clear, multi-generational peaks and troughs, yet they are not strictly periodic, because the time between consecutive peaks ranges from 4 to 7 years (Gardarsson et al. 2004). Indirect evidence suggests that fluctuations of the dominant midge species, Tanytarsus gracilentus Holmgren, are driven by resource interactions with their primary food, benthic

81 diatoms and detritus (Ingvason et al. 2004). While almost all of the 20 species of midges in the

82 lake show synchronous population fluctuations, the fluctuations of $T$. gracilentus are the most

83 extreme ( 5 orders of magnitude) and, at peak abundances, this species makes up roughly $80 \%$ of

84 the midge population by numbers (Gardarsson et al. 2004). In the 23-year (46-generation) time

85 series from 1977 to 1999 , the adult body size of $T$. gracilentus decreased during the generations

86 before population collapse, suggesting resource limitation leading up to troughs in the cycles

87 (Einarsson et al. 2002). Furthermore, a mathematical model of $T$. gracilentus-diatom-detritus

88 interactions that was fit to time-series data on adult midge fluctuations revealed complex

89 dynamics with alternative states representing either a high-amplitude cycle or a moderately high

90 stable point; the irregular period of midge fluctuations could be explained by the midge

91 population exiting the high-amplitude cycles to spend a stochastic duration of time near the stable 
92 point (Ives et al. 2008). While these empirical and theoretical results support the hypothesis that

93 midge fluctuations arise from consumer-resource interactions within Lake Mývatn, they are

94 based solely on data from fluctuations in adult midges. No information has been available to test

95 whether diatom dynamics are consistent with exploiter-victim cycles.

96 Here, we use the hindsight offered by paleoecological methods to test whether the

97 dynamics of midges and benthic diatoms could be the result of consumer-resource interactions.

98 Paleoecological approaches are typically used to address ecosystem-level questions, because they

99 provide synoptic information about a system ( $\mathrm{Smol} 2010)$. This retrospective approach has been

100 used successfully to quantify both algal periodicity (Carpenter and Leavitt 1990) and

101 invertebrate-algal interactions (Leavitt et al. 1989), but never to evaluate the interaction between

102 the two. Here, we combine approaches for the first time, develop novel state-space models to

103 measure reciprocal interactions between herbivores and their resources, and test the population-

104 level hypothesis that fluctuations in diatom and midge abundances are consistent with dynamics

105 expected in tightly coupled consumer-resource interactions. We analyzed two sediment cores

106 from Lake Mývatn representing the period 1975-2003. This time period corresponds closely to

107 our data on midge abundances obtained through trapping adults that began in 1977, and

108 Hauptfleisch et al. (2012) validated the estimates of midge abundances obtained from

109 sedimentary egg counts against the monitoring estimates of adult abundances. From a second

110 core we assayed an array of pigments representing diatoms (diatoxanthin), cyanobacteria that

111 occur in the water column and therefore are not a major component of midge food (echinenone),

112 subdominant cryptophytes (alloxanthin) not heavily consumed by midges, and general indicators

113 of algal abundance that exhibit either robust chemical stability ( $\beta$-carotene) or are highly labile 
114 (chlorophyll-a) (Leavitt and Hodgson 2001). We anticipated that only diatoms would show

115 dynamics consistent with consumer-resource cycles.

116 To assess the dynamics of midges (egg capsules) and primary producers (pigments), we

117 first analyzed the temporal correlations between these variables. These correlation analyses are

118 complicated by autocorrelation, the tendency of many time series to show correlations between

119 successive samples. Although the complications introduced by autocorrelation are well-known in

120 the statistical and ecological literature, only recently have these complications been

121 acknowledged in the paleoecological literature (Blaauw et al. 2010). We then address the more

122 specific question of whether diatoms increase in abundance when midges are rare and whether

123 midges decrease in abundance when diatoms are rare. The midge population peaks that occur

124 every 4-7 years accentuate the problem of sediment mixing that confronts all paleoecological

125 studies; biotic and abiotic disturbances mix the sediment so that a given stratum contains a

126 mixture of material deposited at different times. This is a form of measurement error that can blur

127 a signal, especially by spreading peaks or filling troughs in the cyclic fluctuations of the variables

128 of interest (Leavitt and Carpenter 1989). Therefore, we developed a statistical method that

129 accounts for sediment mixing to give a more-accurate depiction of population time series from

130 sediment cores. Our overall goal is to show how paleoecological approaches can resurrect

131 historical patterns of population dynamics, provided requisite statistical care is given. In our

132 specific case, we use this approach to give the first direct evidence that consumer-resource

133 interactions could drive the sustained, multi-year fluctuations in midge population dynamics

134 found in Lake Mývatn.

135

136

Methods

137

Study system 
139 volcanic area formed by basaltic lava flows (Thorarinsson 1979). Most of the inflow is from

140 groundwater flowing through lava fields, and the resulting high nutrient inputs make the lake

141 highly eutrophic. The maximum natural depth is $4.2 \mathrm{~m}$, with an average depth of $2.5 \mathrm{~m}$. The lake

142 is divided into a north basin $\left(8.5 \mathrm{~km}^{2}\right)$ and a south basin $\left(28.2 \mathrm{~km}^{2}\right)$. Water inflow is

143 predominantly from cold and warm springs along the eastern shore. Due to its passage through

144 volcanic basalts, the spring waters contain high concentrations of phosphate $(1.62 \mu \mathrm{M})$, silica and

145 other dissolved solids, and have a pH ranging between 8.3 and 9.2 (Ólafsson 1979a). The water

146 column is well mixed during the summer months, while thermal stratification and hypoxia occur

147 locally in mid winter (Ólafsson 1979b).

148 The Icelandic name Mývatn means midge lake after its enormous chironomid swarms.

149 During high-midge years, T. gracilentus is by far the most abundant midge species. It has two

150 generations per year, with adults emerging over a 2-3 week period in each of June and late July-

151 August. Gut content analysis of T. gracilentus shows a diet of roughly equal parts diatoms and

152 detritus (Ingvason et al. 2004), with much of the detritus likely frass from previous generations

153 and hence coming ultimately from diatoms. Total net primary production for Lake Mývatn in

154 1972-1973 was about $350 \mathrm{~g} \mathrm{C} / \mathrm{m}^{2} / \mathrm{yr}$ (Jonasson 1979, Jonasson and Adalsteinsson 1979), with

155 most of this from benthic diatoms $\left(220 \mathrm{~g} \mathrm{C} / \mathrm{m}^{2} / \mathrm{yr}\right.$ based on the $1973-1974$ silica budget of the

156 lake, Ólafsson 1979a); in 2000-2001, Thorbergsdóttir et al. (2004) estimated total benthic

157 production of 250 and $340 \mathrm{~g} \mathrm{C} / \mathrm{m}^{2} / \mathrm{yr}$ at two sites using in situ oxygen flux chambers. In addition,

158 extensive lake floor areas of the south basin exhibit loose mats of filamentous green algae

159 (Cladophorales), the extent of which varies greatly on a decadal scale (Einarsson et al. 2004).

160 Blooms of cyanobacteria (Anabaena spp.) occur in most years (Jonasson and Adalsteinsson 1979,

161 Einarsson et al. 2004). 
165 (Brinkhurst et al. 1969) from 3.75-m deep sites <1 m apart in a sheltered bay, Breida by Höfdi, on 166 the east side of Lake Mývatn in June 2006 (Fig. 1). Cores KB-1 and KB-2 were 32- and 34-cm

167 long, respectively, and composed of diatomaceous gyttja (Troels-Smith 1955, Aaby and Berglund 168 1986), or massive and very moist diatomaceous ooze in the terminology of Schnurrenberger et al.

169 (2003). Core KB-1 was analyzed for loss on ignition (LOI) and arthropod microfossils

170 (cladoceran exuviae and chironomid egg capsules) by Hauptfleisch et al. (2012). Core KB-2 was

171 used for the pigment analysis presented here. The cores were extruded in a vertical position

172 aboard the boat, the outermost $0.5-\mathrm{cm}$ layer of smearing was removed with a spatula, and they

173 were then sliced at $0.5-\mathrm{cm}$ intervals. The samples were placed in plastic bags, sealed and

174 transported in a cooler box immediately to the laboratory on the lakeshore where they were stored 175 at $4{ }^{\circ} \mathrm{C}$.

176 For cores KB-1 and KB-2, we first removed the uppermost $10 \mathrm{~cm}$, as these sediments 177 were highly flocculent and largely uncompacted. The time scale of the cores was fine-tuned by 178 matching the profile of the sediment with known events including documented peaks in 179 chironomid abundances $(1979,1987,1992,2000)$ and a tephra layer from an eruption in 180 Grimsvotn volcano in 2004 (Hauptfleisch et al. 2012). We regressed the time of these events 181 against core depth using a quadratic curve, and all results are subsequently presented in terms of 182 this time scale. The analyzed sections of the cores represent the time period 1975-2004, and the 183 time intervals corresponding to $0.5-\mathrm{cm}$ slices ranged from $0.81 \mathrm{yr}$ at the bottom of the core to $1840.30 \mathrm{yr}$ at the top, reflecting compaction of the lower sediments. 
To estimate water content and organic matter content, $1 \mathrm{ml}$ of wet sediment was placed in

186 ceramic crucibles and dried at $80^{\circ} \mathrm{C}$ for $24 \mathrm{~h}$. The dried samples were combusted in a preheated

187 furnace at $550^{\circ} \mathrm{C}$ for $1 \mathrm{~h}$, cooled in a desiccator for $30 \mathrm{~min}$, and weighed at room temperature

188 (Håkanson and Jansson 1983). For additional background data, diatom proportions (Fragilaria

189 spp. vs. non-Fragilaria spp.) were counted in the combusted sediment samples.

Pigments

192

193 were extracted from lyophilized (48 h, $0.01 \mathrm{~Pa})$ whole sediment samples, filtered (0.2- $\mu \mathrm{m}$ pore),

194 and dried under pure $\mathrm{N}_{2}$ gas using the standard methods of Leavitt and Hodgson (2001).

195 Diatoxanthin, echinenone, alloxanthin, $\beta$-carotene, and chlorophyll- $a$ were isolated and

196 quantified using an Agilent model 1100 high-performance liquid chromatography (HPLC)

197 system equipped with photo-diode array and fluorescence detectors, and calibrated with authentic

198 standards. All pigment concentrations are expressed as nmol pigment/g sediment C, a metric

199 which is linearly correlated to annual algal standing stock in whole-lake calibration studies

200 (reviewed in Leavitt and Hodgson 2001).

201

Chironomid eggs

203 We used chironomid eggs as a proxy for chironomids, because they are much more

204 abundant in the sediment and easier to handle than larval head capsules. Egg capsules cannot be

205 identified to species, however, so we cannot separate the different species of midges. For

206 counting, $2 \mathrm{ml}$ of wet sediment were deflocculated by heating in $10 \% \mathrm{KOH}$ (weight/volume) at

$20780^{\circ} \mathrm{C}$ for $2 \mathrm{~h}$ and sieved through a $63-\mu \mathrm{m}$ mesh. The residue was separated by floatation in water 
208 into animal exoskeletal fragments and sand grains. Chironomid egg capsules were identified by

209 their oval, usually slightly asymmetrical shape and smooth surface. The results of the analysis of

210 chironomid egg capsules were published by Hauptfleisch et al. (2012).

214 of the significance of correlations between two variables $Y_{1}$ and $Y_{2}$ assume that the values of the

215 variable $Y_{1}$ are independent of each other, as are the values of $Y_{2}$. However, biological processes

216 are often autocorrelated through time; midge and algal abundances might remain at high or low

217 levels for months or years (Einarsson et al. 2004, Gardarsson et al. 2004). Because positive

218 autocorrelation causes a variable of interest to fluctuate slowly over the possible range of values

219 it can take, autocorrelation can increase type I errors (false positives) in statistical tests of

220 correlation between two variables.

221 To account for possible temporal autocorrelation, we performed the following parametric

222 bootstrap procedure. We first fit an autoregressive-moving average (ARMA) model to each time

223 series. $\operatorname{ARMA}(p, q)$ models have the form

$$
y(t)-\mu=\sum_{i=1}^{p} \beta_{i}(y(t-1)-\mu)+\sum_{j=0}^{q} \alpha_{j} \varepsilon(t-j)
$$

225 where $y(t)$ is the value of a variable in sediment stratum $t, \mu$ gives the mean of $y(t), \beta_{i}$ are the

226 autoregressive coefficients, $\varepsilon_{t}$ is a temporally independent random variable, and $\alpha_{j}$ are the moving

227 average coefficients (Box et al. 1994, Ives et al. 2010). Thus, the first term on the right-hand side

228 is the autoregressive component of the model, and the second term is the moving average

229 component; the greater the values of $p$ and $q$, the longer the time lags included in the AR and MA 
230 components of the model. ARMA models are flexible enough to fit potentially complex patterns

231 of autocorrelation (Ives et al. 2010), and we used Akaike's Information Criterion corrected for

232 small sample sizes (AICc) to select the values of $p$ and $q$ that give the best fits to the time series.

233 We then simulated data from the best-fitting ARMA models and computed pairwise Pearson's

234 correlation coefficients from the simulated data sets. Repeating this for 100,000 simulated data

235 sets gives the approximate distribution of the estimator (Efron and Tibshirani 1993) of the

236 correlation coefficient under the null hypothesis that the time series $y_{1}(t)$ and $y_{2}(t)$ are

237 independent but temporally autocorrelated, and we used this to compute p-values. Because we

238 were interested in fluctuations in the response variables, we detrended the response variables with

239 a quadratic function, $y(t)=c_{0}+c_{1} t+c_{2} t^{2}$, and standardized the residuals to have standard

240 deviation 1 (Patoine and Leavitt 2006). This removes possible degradation or transformation of

241 pigments through time.

242 When considering correlations among several variables, we also used the bootstrap

243 procedure to obtain $\mathrm{p}$-values corrected for multiple comparisons using an approach comparable to

244 a sequential (Holm) Bonferroni correction (Holm 1979). We first ordered the $K$ correlation

245 coefficients from lowest to highest p-value. For the first correlation coefficient, we counted the

246 proportion of simulated data sets (including all variables) for which one or more of the $K$

247 correlation coefficients had a lower p-value; this proportion gives the corrected p-value for the

248 first correlation coefficient. We then excluded this correlation coefficient from the simulated data

249 sets and repeated the procedure for the second correlation coefficient, asking what proportion of

250 the simulated data sets had one or more of the $K-1 \mathrm{p}$-values lower than the observed p-value of

251 the second correlation coefficient. We repeated this procedure, excluding correlation coefficients

252 until the corrected p-value exceeded 0.05 . This approach allowed us to report p-values that

253 account for the multiple correlation coefficients we computed. 

assessing correlations among variables, we also wanted to test the more-mechanistic hypothesis that high midge abundance (egg capsules) caused diatom abundance (diatoxanthin) to decrease, while high diatom abundance allowed midges to increase. For this we designed a state-space model (Harvey 1989) that explicitly incorporates both autocorrelation and measurement error 261 generated by sediment mixing. We performed analyses not only for diatoxanthin, but also for 262 echinenone, alloxanthin, $\beta$-carotene, and chlorophyll- $a$; we expected the strongest interaction 263 between midges and diatoms, so these other pigments serve as statistical controls. Note, however, 264 that they are not independent; for example, diatoms contain not only diatoxanthin but also $\beta$ 265 carotene and chlorophyll- $a$. Differences in chemical stability of the latter two pigments allowed 266 us to evaluate whether our approach was additionally subject to diagenetic effects of post-

267 depositional pigment degradation. As reviewed in Leavitt and Hodgson (2001), the carotenoids 268 used in this study are all well preserved in lake sediments, in contrast to ubiquitous chlorophyll- $a$ 269 which is rapidly transformed or discolored in surface deposits.

270 The state-space model comprises two sets of equations, one describing process error 271 (biological variability) and the other measurement error (including vertical mixing of sediment).

272 The process equations are

$$
\begin{aligned}
& \log x_{1}(t)=b_{10}+\tau(t)\left[b_{11}\left(\log x_{1}(t-1)-b_{10}\right)+b_{12} \log x_{2}(t-1)\right]+\varepsilon_{1}(t) \\
& \log x_{2}(t)=b_{20}+\tau(t)\left[b_{22}\left(\log x_{2}(t-1)-b_{20}\right)+b_{21} \log x_{1}(t-1)\right]+\varepsilon_{2}(t)
\end{aligned},
$$

274 where $\log x_{1}(t)$ is the natural logarithm of the concentration of the algal pigment of interest, and $275 \log x_{2}(t)$ is $\log$ midge egg capsule abundance. We modeled variables on a log scale because we 
276 expect ecological processes to act multiplicatively; taking the log allows the use of a linear

277 autoregressive model and is formally equivalent to a Gompertz multiplicative population model

278 (Dennis and Taper 1994). The samples $t$ give the consecutive 0.5 -cm core slices rescaled to time

279 in years (see Methods: Coring and sampling). To account for sediment compaction, $\tau(t)$ gives the

280 time interval between the core samples at $t-1$ and $t$. The Gaussian random variables $\varepsilon_{i}(t)$ with

281 means zero and variances $\sigma_{i}^{2}$ represent variation in $\log x_{i}(t)$ between samples. The coefficients $b_{i 0}$

282 give the expected value of $\log x_{i}(t), b_{i i}$ measures the autocorrelation of $\log x_{i}(t)$ from one sample

283 to the next, and $b_{i j}$ measures the effect of $\log x_{j}(t)$ on $\log x_{i}(t)$; thus, if $b_{12}$ is negative, then high

284 midge abundances are associated with decreases in log pigment concentration between samples $t$

285 and $t+1$, and if $b_{21}$ is positive, then high pigment concentrations are associated with increases in

286 log midge egg capsules.

287 The measurement equations are

288

$$
x_{1}(t) *=\sum_{T=0}^{r} a^{T} x(t-T)+\phi_{1}(t)
$$

$$
x_{2}(t) *=\sum_{T=0}^{r} a^{T} u(t-T)+\phi_{2}(t)
$$

289 where $x_{1}(t)^{*}$ and $x_{2}(t)^{*}$ are the observed values of $x_{1}(t)$ and $x_{2}(t)$ at time $t$. Because mixing of

290 sediment is an additive process, the measurement equations are formulated using the

291 untransformed values of $x_{1}(t)$ and $x_{2}(t)$. To account for sediment mixing, the observed values

$292 x_{1}(t)^{*}$ and $x_{2}(t) *$ depend not only on the sedimentation rates of $x_{1}(t)$ and $x_{2}(t)$ at sample $t$, but also

293 on the sedimentation for $r$ core increments into the past (lower sediments). The sedimentation

294 rates $T$ time steps in the past are discounted by the term $a^{T}(a<1)$, so that spatially more-distant

295 sediments have lower mixing with the sediments in sample $t$. This equation makes the

296 simplifying approximation that the sediments in sample $t$ are mixed with lower sediments but not 
297 with sediments above; while this is the case immediately following the deposition of sediment,

298 later mixing with higher sediments will occur (Leavitt and Carpenter 1989). We address this

299 asymmetry in more detail with simulations in Appendix A (online Supplemental Material).

300 Finally, $\phi_{1}(t)$ and $\phi_{2}(t)$ are Gaussian random variables with variances $x_{1}(t) v^{2}{ }_{1}$ and $x_{2}(t) \cup^{2}{ }_{2}$. These

301 variances are proportional to the mean under the assumption that sampling variability is

302 approximately Poisson; this also prohibits negative values of $x_{1}(t)^{*}$ and $x_{2}(t)^{*}$ when the predicted

303 values of $x_{1}(t)$ and $x_{2}(t)$ are small. Because separate cores were taken for algal pigments and

304 midge egg capsules, we assumed zero correlation between $\phi_{1}(t)$ and $\phi_{2}(t)$.

305 We fit the state-space model given by equations 2 and 3 using an extended Kalman filter

306 to calculate the likelihood function (Harvey 1989). Maximum likelihood parameter values were

307 estimated for 11 variables: $b_{10}, b_{20}, b_{12}, b_{21}, b_{11}, b_{22}, a, \sigma_{1}^{2}, \sigma_{2}^{2}, v_{1}^{2}$, and $v_{2}^{2}$. We tested the

308 statistical significance of the effect of midge abundance on pigments, $b_{12}$, and pigments on midge

309 abundance, $b_{21}$, using likelihood ratio tests to compare the full 11-parameter model with the

310 reduced 9-parameter model in which $b_{12}=b_{21}=0$, as well as the separate 10-parameter models

311 with either $b_{12}=0$ or $b_{21}=0$. Likelihood ratio tests are based on the asymptotic approximation

312 that with large sample sizes, the log-likelihood ratios are $\chi^{2}$ distributed with degrees of freedom

313 equal to the difference in the number of parameters between models (Harvey 1989). We

314 performed these analyses for $r=3$ which sets the maximum mixing distance at 3 core sections (2

$315 \mathrm{~cm})$. To account for possible trends in variables through time, we first quadratically detrended all

316 variables. After detrending, we added a constant to each time series to give it the same minimum

317 value as the non-detrended time series, and then standardized to give each time series a variance

318 of one. For fitting the model, we assumed that the initial values of $x_{i}(0)$ were their observed

319 values. The initial variances of $\log x_{1}(0)$ and $\log x_{2}(0)$ were set to $\sigma_{1}^{2}$ and $\sigma_{2}^{2}$, with zero 
320 covariance. Our statistical approach allows direct evaluation of whether the dynamics of midges

321 and algae observed in the sediment are consistent with strong consumer-resource interactions.

\section{Validation using a simulation model}

Because the midge dynamics inferred from adult data are not strictly periodic, we tested

325 whether the state-space approach (Eqs. 2, 3) could detect negative effects of midges on diatoms

326 and positive effects of diatoms on midges even for non-periodic data that we would expect in

327 Lake Mývatn. We generated simulated core data by predicting midge and diatom abundances

328 from the midge-diatom-detritus model that we previously fit to the adult midge time series (Ives

329 et al. 2008); this model showed possible alternative states underlying Tanytarsus gracilentus

330 dynamics. Using the model to generate midge and diatom abundances, we then simulated the

331 sedimentation process including both deposition and mixing between adjacent sediment layers;

332 details are giving in Appendix A (online Supplemental Material). We fit the simulated data using

333 the same procedure as we used for the real sediment core data. If the model fit to simulated data

334 gives similar results to those when fit to the real data, then we can be confident that our approach

335 will detect consumer-resource interactions even when these interactions do not lead to cycles

336 with regular periods.

\section{RESULTS}

339 Our analyses focus on the interactions between midge abundance (egg capsules) and the

340 abundances of diatoms (diatoxanthin), cyanobacteria (echinenone), cryptophytes (alloxanthin),

341 and total algal abundance as recorded by chemically stable ( $\beta$-carotene) and labile biomarkers

342 (chlorophyll-a) (Appendix B, Fig. B1). As expected, the strongest correlations were recorded 
343 between the two markers of total algal abundance, as well as total algal abundance and the

344 predominant benthic (diatom) and planktonic (cyanobacteria) algal groups (Table 1). Weaker

345 correlations were observed between planktonic cyanobacteria (echinenone) and cryptophytes

346 (alloxanthin). In contrast, only concentrations of the pigment diatoxanthin (diatoms) were

347 correlated significantly ( -0.37$)$ with midge egg capsules (Table 1$)$.

348 Statistical significance of these correlations (Table 1) was determined by parametric

349 bootstrapping to account for autocorrelation in the individual time series. We also computed p-

350 values using standard Pearson correlation coefficients (Table 2). In all cases the p-values ignoring

351 autocorrelation were smaller than those computed when accounting for autocorrelation; for

352 example, the standard $p$-value for the correlation of -0.37 between midge egg capsules and

353 diatoxanthin was 0.012 , whereas the bootstrap estimate was 0.039 . This comparison underscores

354 the need to account for autocorrelation when comparing fossil time series.

355 Diatoxanthin showed peaks in 1977, 1983, 1987, and 1999 that preceded peaks in midge

356 egg capsule counts (Fig. 2). This pattern is consistent with consumer-resource interactions in

357 which increases in diatoms occur at low midge abundance, and increases in midges occur at high

358 diatom abundance. In the state-space model (Eqs. 2, 3) the estimate for the effect of midges on

359 diatoxanthin is $b_{12}=-0.90$, and the effect of diatoxanthin on midges is $b_{21}=0.46$ (Table 3 ); both

360 of these coefficients are significantly different from zero separately $\left(b_{12}: \chi^{2}{ }_{1}=13.08, \mathrm{P}=0.0003\right.$;

$\left.361 b_{21}: \chi_{1}^{2}=6.46, \mathrm{P}=0.011\right)$ and together $\left(\chi_{2}^{2}=26.84, \mathrm{P}<0.0001\right)$. In addition, the analysis of

362 midge egg capsules and $\beta$-carotene gave a negative estimate of $b_{12}=-0.54\left(\chi^{2}{ }_{1}=9.79, \mathrm{P}=\right.$

$3630.0017)$ and a positive estimate of $b_{21}=0.33\left(\chi^{2}{ }_{1}=4.04, \mathrm{P}=0.044\right)$, similar to but weaker than

364 the interactions inferred between midges and diatoxanthin. None of the other pigments showed

365 statistically significant values of $b_{12}$ and $b_{21}$, suggesting that the associated algae were not 
366 involved in consumer-resource cycles (Table 3). Furthermore, the absence of significant

367 estimates if $b_{12}$ and $b_{21}$ for ubiquitous chlorophyll $a$ confirms that models can be influenced by 368 post-depositional degradation of fossil records.

369 The state-space model fit to midge egg capsules and diatoxanthin gives information not 370 only about interaction strengths $b_{12}$ and $b_{21}$, but also about other properties inferred from the data.

371 The best-fitting state-space model (Table 3) gave an estimate of $a=0.55\left(\chi^{2}{ }_{1}=9.13, \mathrm{P}=0.0025\right)$.

372 This value of $a$ implies that 0.50 of the diatoxanthin remained in the sediment stratum where it

373 was deposited, while $0.27\left(=a /\left(1+a+a^{2}+a^{3}\right), 0.15,\left(=a^{2} /\left(1+a+a^{2}+a^{3}\right)\right.\right.$ and $0.08\left(=a^{3} /\left(1+a+a^{2}+a^{3}\right)\right.$

374 represent sediment from slices $0.5,1.0$, and $1.5 \mathrm{~cm}$ below the observed core slice. This value of $a$

375 is similar for other pigments, except for the lower value estimated for echinenone. The fitted

376 value of $b_{11}$ is close to zero, implying that there is little autocorrelation in diatom abundances

377 through time that is not explained by midge abundance; in contrast, $b_{22}=1.29$, implying strong

378 autocorrelation in midge abundance. In contrast to these model parameters, other model

379 parameters were not informative. Specifically, the magnitudes of the process and sampling errors

$380 \quad\left(\sigma^{2}{ }_{i}\right.$ and $\left.v_{i}^{2}\right)$ often traded off against each other, so that $\sigma_{i}^{2}>0$ and $v_{i}^{2}=0$, or $\sigma_{i}^{2}=0$ and $v_{i}^{2}>0$.

381 This is the result of the difficulty of statistically separating process error from measurement error.

382 To validate the state-space modeling approach, we simulated midge and diatom

383 abundance data using the model that had been fit to adult $T$. gracilentus data collected during

384 1977-2002 (Ives et al. 2008), and then simulated the sedimentation process including mixing

385 among layers (Appendix A). As we found for the real core data, the analysis of the simulated core

386 data identified a negative value of $b_{12}=-0.55$ and positive value of $b_{21}=0.82$, both of which

387 were statistically significant. The simulations show that the state-space model (Eq. 2 and 3) is 
388 robust to pronounced but complex (aperiodic) variation in population abundance caused by

389 consumer-resource interactions.

Paleoecological analysis of fossil midges (egg capsules) and diatoms (diatoxanthin)

393 provided direct support for the hypothesis that the dramatic midge population fluctuations in

394 Lake Mývatn are driven mainly by consumer-resource interactions between midges and their

395 food. Our state-space model showed that high midge egg capsule densities were associated with

396 decreases in diatoxanthin concentration and, in turn, high diatoxanthin concentrations were

397 associated with increases in midges. Furthermore, $\beta$-carotene (algae) showed a similar though

398 weaker pattern, consistent with the fact that diatoms are a main component of the algal

399 assemblage, and that changes in concentration of diatoxanthin and $\beta$-carotene were highly

400 correlated (Table 1). In contrast, none of other pigments showed significant correlation with

401 midge abundance.

402 Although concomitant changes in diatoms and midges do not prove that consumer-

403 resource interactions underlie the observed decadal-scale population fluctuations, several lines of

404 evidence suggest that population fluctuations are not driven by other trophic interactions within

405 Lake Mývatn. Two other general possibilities are bottom-up effects on diatoms (i.e., some other

406 interaction drives diatom fluctuations, and midges follow) and top-down effects on midges (i.e.,

407 some other interaction drives midge fluctuations, and diatoms follow). For the bottom-up

408 alternative, there would have to be a driver of diatom fluctuations other than midges. Diatoms are

409 the dominant group of primary producers in the lake, accounting for over $50 \%$ of primary

410 production (see Methods: Study system). Furthermore, most primary production is benthic rather 
411 than pelagic, and diatoms are the dominant benthic primary producers $(>95 \%$ of them are benthic

412 Fragilariaceae spp., Einarsson 1982). Thus, if there were an as yet unidentified driver of diatom

413 fluctuations, this driver would have to be strong enough to cause large fluctuations in benthic

414 primary production. Possible candidates for strong drivers are the mainly pelagic herbivore,

415 Daphnia longispina, and the epibenthic large-bodied cladocerans, and these do fluctuate in

416 synchrony with midges (Einarsson and Örnólfsdóttir 2004). Nonetheless, midges perform more

417 than $80 \%$ of the secondary production in the benthos (Lindegaard and Jónasson 1979), and

418 therefore are much better candidates for drivers of diatom abundance. Another possible candidate

419 for a driver of diatom fluctuations is Anabaena spp. that limit the growth of diatoms via shading.

420 Nonetheless, in the core data Anabaena spp. (as measured by echinenone) fluctuate in synchrony

421 with diatoms (diatoxanthin) (Table 1), which argues against shading from Anabaena spp. driving 422 diatom fluctuations.

423 The second general alternative hypothesis is that top-down forces generate fluctuations in 424 midges, and diatoms fluctuate in response. The obvious candidate for a top-down driver of midge 425 fluctuations is stickleback fish. Gut content analyses show that sticklebacks consume midges, 426 with midges comprising up to $56 \%$ of gut contents in a high-midge year and $9 \%$ in a low-midge 427 year (Gíslason et al. 1998). Nonetheless, the dominant midge, T. gracilentus, is better protected 428 than other midge species in their heavily constructed tubes and seems to be avoided by 429 sticklebacks. Furthermore, analyses of the time series of midges and sticklebacks (Einarsson et al. 430 2002) did not show the out-of-phase fluctuations that is expected for predator-prey cycles, instead 431 suggesting that sticklebacks follow rather than drive midge fluctuations. In addition to predators, 432 it is also possible that there is an unidentified parasite or pathogen that drives midge population 433 fluctuations, although we have little evidence for this.

434 Historical changes in grazing intensity and lake hydrology do not appear to have biased 
435 the formation of the fossil record, nor the reliability of sedimentary time series as metrics of past

436 population abundance. Although intensification of herbivory is known to increase the rates of

437 deposition of algae and their pigments (Leavitt and Carpenter 1990), empirical (Leavitt et al.

438 1989) and modeling evidence (Cuddington and Leavitt 1999) show that this effect is limited to

439 less than a year in duration. Similarly, ecosystem-scale nutrient mass budgets reveal that over

$44090 \%$ of inflow silica is retained in the lake (Ólafsson 1979a), mainly due to uptake by and

441 deposition in diatoms (Opfergelt et al. 2011).

\section{Statistical Methods}

444 We developed a bootstrap method for determining the statistical significance of

445 correlations between two time series when each has temporal autocorrelation. Comparing its

446 results to standard correlations (Table 2) shows that standard correlations are likely to generate

447 type I errors (false positives). This can be explained simply with an example. Suppose there are

448 two 100-year time series that both show cycles with strict 10-year periods yet are independent.

449 There is a $20 \%$ chance that they fluctuate in either perfect synchrony or perfect asynchrony

450 (lagged by 5 years) for 100 years, which would clearly show very high statistical significance in a

451 standard correlation test; even if they were lagged by 1 or 6 years, the standard correlations

452 would likely be significant. Thus, it would be easy to get statistically significant correlations even

453 though we know that the time series are independent. Our bootstrap approach corrects for

454 autocorrelation and hence does not suffer from this potential source of type I errors.

455 Our state-space model takes a more-mechanistic approach, modeling explicit interactions

456 between variables and incorporating measurement error that accounts for sediment mixing. The

457 mathematical description of sediment mixing is simplistic, assuming that sediment layers below a

458 given strata have an influence that tapers off geometrically with depth. This is similar to the 
assumption used by Blaauw and Christen (2011) to construct a model relating sediment depth to

460 age determined by radiocarbon dating. Nonetheless, there are numerous bioturbation (Kristensen

461 et al. 2012) models that incorporate much more sophisticated assumptions about the physical and

462 biological processes underlying sediment mixing (Sandnes et al. 2000, Meysman et al. 2005,

463 Schiffers et al. 2011). We have not attempted to incorporate the complexities of bioturbation into

464 our model, because the information needed to apply these approaches is unknown for our system.

465 Therefore, our approach matches the level of detail in the model to the data we have. When

466 applied to simulated data (Appendix A, online Supplemental Material), the approach did identify

467 the effects of sedimentation in smoothing the fluctuations in deposition rates. Despite this

468 smoothing effect, the state-space model still identified strong interactions between midges and

469 diatoms in both simulated and real data.

\section{Conclusion}

Our analyses of sediment core data give strong support to the midge-diatom consumer-

473 resource hypothesis to explain the fluctuations in midge and diatom abundances in Lake Mývatn.

474 Sediment cores are the only source of information about diatom fluctuations in Lake Mývatn, 475 because continuous long-term monitoring was not performed. Our example thus illustrates the 476 benefits of paleoecology to reconstruct history and extract missing information that is preserved 477 in sediment cores. This information is not limited to broad, ecosystem-level processes, but can 478 also be used to understand the population dynamical interactions between species.

\section{ACKNOWLEDGMENTS}

We thank Eva Pier for field assistance and Theodóra Matthíasdóttir for lab work. Two 482 anonymous reviewers provided great suggestions that improved this work. The study was funded 
by the European Union "Eurolimpacs"-project GOCE-CT-2003-505540 and by Icelandic Centre 484 for Research (RANNÍS) grants no. 050219032 and 080010008. PL acknowledges funding from 485 NSERC (Natural Science and Engineering Research Council of Canada) and funding for ARI 486 was provided in part by US-NSF-DEB-LTREB-1052160.

\section{REFERENCES}

Aaby, B., and B. E. Berglund. 1986. Characterisation of peat and lake deposits. Pages 231-246 in B. E. Berglund, editor. Handbook of Holocene Palaeoecology and Palaeohydrology. John Wiley and Sons, Chichester, NY.

Berryman, A. A. 1976. Theoretical explanation of mountain pine beetle dynamics in lodgepole pine forests. Environmental Entomology 5:1225-1233.

Berryman, A. A., G. D. Amman, and R. W. Stark. 1978. Theory and practice of mountain pine beetle management in lodgepole pine forests. Forest, Wildlife and Range Experimental Station, University of Idaho, Moscow, Idaho, USA.

Blaauw, M., K. D. Bennett, and J. A. Christen. 2010. Random walk simulations of fossil proxy data. Holocene 20:645-649.

Blaauw, M., and J. A. Christen. 2011. Flexible paleoclimate age-depth models using an autoregressive gamma process. Bayesian Analysis 6:457-474.

Box, G. E. P., G. M. Jenkins, and G. C. Reinsel. 1994. Time series analysis: forecasting and control. Third edition. Prentice Hall, Englewood Cliffs, New Jersey, USA. applied to studies on the bacteria and tubificid oligochaetes inhabiting aquatic sediments. Journal of the Fisheries Research Board of Canada 26: 2581-2593. 
506 Carpenter, S. R., and P. R. Leavitt. 1991. Temporal variation in a paleolimnological record $507 \quad$ arising from a trophic cascade. Ecology 72: 277-285.

508 Cuddington, K., and P. R. Leavitt. 1999. An individual-based model of pigment flux in lakes:

509 Implications for organic biogeochemistry and paleoecology. Canadian Journal of

$510 \quad$ Fisheries and Aquatic Science 56: 1964-1977.

511 Dennis, B., and B. Taper. 1994. Density dependence in time series observations of natural

512 populations: estimation and testing. Ecological Monographs 64:205-224.

513 Dwyer, G., J. Dushoff, and S. H. Yee. 2004. The combined effects of pathogens and predators on $514 \quad$ insect outbreaks. Nature 430:341-345.

515 Efron, B., and R. J. Tibshirani. 1993. An introduction to the bootstrap. Chapman and Hall, New $516 \quad$ York.

517 Einarsson, Á. 1982. The paleolimnology of Lake Myvatn, northern Iceland: plant and animal 518 micro-fossils in the sediment. Freshwater Biology 12:63-82.

519 Einarsson, Á., A. Gardarsson, G. M. Gíslason, and A. R. Ives. 2002. Consumer-resource 520 interactions and cyclic population dynamics of Tanytarsus gracilentus (Diptera: $521 \quad$ Chironomidae). Journal of Animal Ecology 71:832-845.

522 Einarsson, Á., and R. D. Gulati, editors. 2004. Ecology of Lake Myvatn and the River Laxa: 523 temporal and spatial variation.

524 Einarsson, Á., and E. B. Örnólfsdóttir. 2004. Long-term changes in benthic Cladocera 525 populations in Lake Myvatn, Iceland. Aquatic Ecology 38:253-262.

526 Einarsson, Á., G. Stefánsdóttir, H. Jóhannesson, J. S. Ólafsson, G. M. Gíslason, I. Wakana, G. 527 Gudbergsson, and A. Gardarsson. 2004. The ecology of Lake Myvatn and the River Laxa: $528 \quad$ Variation in space and time. Aquatic Ecology 38:317-348. 
529 Gardarsson, A., Á. Einarsson, G. M. Gíslason, T. Hrafnsdóttir, H. R. Ingvason, E. Jónsson, and J.

530 S. Ólafsson. 2004. Population fluctuations of chironomid and simuliid Diptera at Myvatn $531 \quad$ in 1977-1996. Aquatic Ecology 38:209-217.

532 Gíslason, G. M., A. Gudmundsson, and Á. Einarsson. 1998. Population densities of the three533 spined stckleback (Gasterosteus aculeatus L.) in a shallow lake. Verh Internat Verein $534 \quad$ Limnol 26:2244-2250.

535 Håkanson, L., and M. Jansson. 1983. Principles of lake sedimentology. Springer, New York, NY. 536 Harvey, A. C. 1989. Forecasting, structural time series models and the Kalman filter. Cambridge 537 University Press, Cambridge, U.K.

538 Hauptfleisch, U., Á. Einarsson, T. J. Andersen, A. Newton, and A. Gardarsson. 2012. Matching 539 thirty years of ecosystem monitoring with a high resolution microfossil record. Freshwater Biology 57:1986-1997.

541 Holm, S. 1979. A simple sequentially rejective multiple test procedure. Scandinavian Journal of 542

543 Ingvason, H. R., J. S. Ólafsson, and A. Gardarsson. 2004. Food selection of Tanytarsus 544 gracilentus larvae (Diptera: Chironomidae): an analysis of instars and cohorts. Aquatic $545 \quad$ Ecology 38:231-237.

546 Ives, A. R., K. C. Abbott, and N. L. Ziebarth. 2010. Analysis of ecological time series with 547 $\operatorname{ARMA}(\mathrm{p}, \mathrm{q})$ models. Ecology 91:858-871.

548 Ives, A. R., Á. Einarsson, V. A. A. Jansen, and A. Gardarsson. 2008. High-amplitude fluctuations 549 and alternative dynamical states of midges in Lake Myvatn. Nature 452:84-87.

550 Jónasson, P. M., editor. 1979. Ecology of eutrophic, subarctic Lake Myvatn and the River Laxa. $551 \quad$ Oikos. 
Jónasson, P. M., and H. Adalsteinsson. 1979. Phytoplankton production in shallow eutrophic Lake Myvatn, Iceland. Oikos 32:113-138.

554 Kendall, B. E., C. J. Briggs, W. W. Murdoch, P. Turchin, S. P. Ellner, E. McCauley, R. M. Nisbet, and S. N. Wood. 1999. Why do populations cycle? A synthesis of statistical and

Krebs, C. J. 2011. Of lemmings and snowshoe hares: the ecology of northern Canada. Proceedings of the Royal Society B-Biological Sciences 278:481-489.

Krebs, C. J., S. Boutin, R. Boonstra, A. R. E. Sinclair, J. N. M. Smith, M. R. T. Dale, K. Martin, and R. Turkington. 1995. Impact of food and predation on the snowshoe hare cycle. Science 269:1112-1115.

Kristensen, E., G. Penha-Lopes, M. Delefosse, T. Valdemarsen, C. O. Quintana, and G. T. Banta. 2012. What is bioturbation? The need for a precise definition for fauna in aquatic sciences. Marine Ecology Progress Series 446:285-302. production on fossil pigment stratigraphies. Journal of Paleolimnology 2:147-158.

Leavitt, P. R., S. R. Carpenter and J. F. Kitchell. 1989. Whole-lake experiments: The annual record of fossil pigments and zooplankton. Limnology and Oceanography 34: 700-717.

Leavitt, P. R., and D. A. Hodgson. 2001. Sedimentary pigments. Pages 295-325 in J. P. Smol, H. J. B. Birks, and W. M. Last, editors. Tracking environmental change using lake sediments. V. 3: Terrestrial, algal and siliceous indicators. Kluwer, Dordrecht, the Netherlands

Lindegaard, C., and P. M. Jónasson. 1979. Abundance, population dynamics and production of zoobenthos in Lake Mývatn, Iceland. Oikos 32:202-227.

Lotka, A. J. 1925. Elements of physical biology. Williams and Wilkins, Baltimore, MD. 
576 McCauley, E., W. A. Nelson, and R. M. Nisbet. 2008. Small-amplitude cycles emerge from stage-structured interactions in Daphnia-algal systems. Nature 455:1240-1243.

578 McCauley, E., R. M. Nisbet, W. W. Murdoch, A. M. de Roos, and W. S. C. Gurney. 1999. Largeamplitude cycles of Daphnia and its algal prey in enriched environments. Nature 402:653656.

Meysman, F. J. R., B. P. Boudreau, and J. J. Middelburg. 2005. Modeling reactive transport in sediments subject to bioturbation and compaction. Geochimica et Cosmochimica Acta 69:3601-3617.

Murdoch, W. W., R. M. Nisbet, E. McCauley, A. M. deRoos, and W. S. C. Gurney. 1998. Plankton abundance and dynamics across nutrient levels: Tests of hypotheses. Ecology 79:1339-1356.

Myers, J. H. 1988. Can a general hypothesis explain population cycles of forest Lepidoptera? Advances in Ecological Research 18:179-242.

Ólafsson, J. 1979a. The chemistry of Lake Mývatn and River Laxá. Oikos 32:82-112.

Ólafsson, J. 1979b. Physical characteristics of Lake Mývatn and River Laxá. Oikos 32:38-66.

Opfergelt, S., E. S. Eiríksdóttir, K. W. Burton, Á. Einarsson, C. Siebert, S. R. Gíslason, and A. N. Halliday. 2011. Quantifying the impact of freshwater diatom productivity on silicon isotopes and silicon fluxes: Lake Myvatn, Iceland. Earth and Planetary Science Letters 305:73-82.

Patoine, A., and P. R. Leavitt. 2006. Century-long synchrony of algal fossil pigments in a chain of Canadian prairie lakes. Ecology 87:1710-1721.

Sandnes, J., T. Forbes, R. Hansen, B. Sandnes, and B. Rygg. 2000. Bioturbation and irrigation in Series 197:169-179. 
600 Schiffers, K., L. R. Teal, J. M. J. Travis, and M. Solan. 2011. An Open Source Simulation Model 601 for Soil and Sediment Bioturbation. PLoS ONE 6.

602 Schnurrenberger, D., J. Russell, and K. Kelts. 2003. Classification of lacustrine sediments based 603 on sedimentary components. Journal of Paleolimnology 29:141-154.

604 Smol, J. P. 2010. The power of the past: using sediments to track the effects of multiple stressors 605 on lake ecosystems. Freshwater Biology, 55: 43-59.

606 Stenseth, N. C. 1999. Population cycles in voles and lemmings: density dependence and phase 607 dependence in a stochastic world. Oikos 87:427-461.

608 Thorarinsson, S. 1979. The postglacial history of the Mývatn area. Oikos 32:17-28.

609 Thorbergsdóttir, I. M., S. R. Gíslason, H. R. Ingvason, and Á. Einarsson. 2004. Benthic oxygen 610 flux in the highly productive subarctic Lake Myvatn, Iceland: In situ benthic flux chamber $611 \quad$ study. Aquatic Ecology 38:177-189.

612 Troels-Smith, J. 1955. Karakterisering af løse jordarter. Danmarks Geologiske Undersøgelse, $613 \quad$ Copenhagen.

614 Turchin, P. 2003. Complex population dynamics: a theoretical/empirical synthesis. Princeton $615 \quad$ University Press, Princeton, NJ.

616 Turchin, P., and I. Hanski. 2001. Contrasting alternative hypotheses about rodent cycles by translating them into parameterized models. Ecology Letters 4:267-276.

618 Turchin, P., S. N. Wood, S. P. Ellner, B. E. Kendall, W. W. Murdoch, A. Fischlin, J. Casas, E. 619 McCauley, and C. J. Briggs. 2003. Dynamical effects of plant quality and parasitism on population cycles of larch budmoth. Ecology 84:1207-1214.

621

622

APPENDIX A 
623 Simulation of midge and diatom abundance data.

624

625 APPENDIX B

626 Stratigraphy of pigments, loss on ignition (LOI), C, N, $\delta^{13} \mathrm{C}$, diatoms, chironomid eggs and

627 Cladocera exuviae in the sediment cores.

628 
629 Table 1: Correlations among six variables from two sediment cores.

Midge

eggs Dia Echin Allox $\beta$-caro

Diatoxanthin $-0.37^{*}$

Echinenone $-0.16 \quad 0.42 *$

Alloxanthin $-0.03 \quad 0.25 \quad 0.34^{*}$

$\beta$-carotene $-0.19 \quad 0.64 * * \dagger \dagger \quad 0.52 * * \quad-0.01$

$\begin{array}{llllll}\text { Chlorophyll- } a & 0.09 & 0.53 * & 0.53 * & 0.17 & 0.77 * * \dagger \dagger\end{array}$

630

$631 * \mathrm{P}<0.05, * * \mathrm{P}<0.01$, calculated from a bootstrap that incorporates autocorrelation (Eq. 1)

$632 \uparrow \mathrm{P}<0.05, \uparrow \uparrow \mathrm{P}<0.01$, calculated from a bootstrap Holm-Bonferroni correct for multiple

633 comparisons that incorporates autocorrelation (Eq. 1)

634

635 
636 Table 2: P-values (2-tailed and not corrected for multiple comparisons) from a standard Pearson 637 correlation test (upper-right triangle) and from the bootstrap (Eq. 1) that accounts for temporal 638 autocorrelation (lower-left triangle).

\begin{tabular}{|c|c|c|c|c|c|c|}
\hline \multicolumn{7}{|c|}{ Midge } \\
\hline & eggs & Dia & Echin & Allox & $\beta$-caro & Chl- $a$ \\
\hline Midge eggs & & 0.012 & 0.29 & 0.87 & 0.20 & 0.52 \\
\hline Diatoxanthin & 0.039 & & 0.002 & 0.08 & 0.0000 & 0.0000 \\
\hline Echinenone & 0.35 & 0.018 & & 0.016 & 0.0001 & 0.0000 \\
\hline Alloxanthin & 0.88 & 0.19 & 0.046 & & 0.98 & 0.23 \\
\hline$\beta$-carotene & 0.27 & 0.0001 & 0.003 & 0.96 & & 0.0000 \\
\hline Chlorophyll- $a$ & 0.67 & 0.011 & 0.011 & 0.43 & 0.0003 & \\
\hline
\end{tabular}

639 
640 Table 3: Parameter estimates from the state-space model given by equations 2 and 3 for each of 641 five pigments.

Coefficient Diatoxanthin Echinenone Alloxanthin $\tilde{\beta}$ carotene Chl- $a$

\begin{tabular}{|c|c|c|c|c|c|}
\hline$b_{11}$ & -0.10 & 1.54 & 0.65 & 1.21 & 1.81 \\
\hline$b_{22}$ & 1.29 & 0.40 & 0.11 & 1.42 & 0.09 \\
\hline$b_{12}$ & $-0.90 * * *$ & 0.00 & -0.10 & $-0.54 * *$ & -0.04 \\
\hline$b_{21}$ & $0.46^{*}$ & -0.24 & $-0.31 * * *$ & $0.33^{*}$ & 0.65 \\
\hline$b_{10}$ & 0.36 & 0.75 & 0.21 & 0.32 & 0.89 \\
\hline$b_{20}$ & -0.03 & 0.33 & -0.08 & -0.03 & 0.06 \\
\hline$a$ & 0.55 & 0.21 & 0.44 & 0.48 & 0.46 \\
\hline$\sigma_{1}$ & 0.39 & 0.00 & 0.38 & 0.00 & 0.00 \\
\hline$\sigma_{2}$ & 0.00 & 0.53 & 0.60 & 0.00 & 0.65 \\
\hline$v_{1}$ & 0.00 & -0.40 & 0.29 & 0.35 & -0.17 \\
\hline $\mathrm{v}_{2}$ & 0.49 & 0.00 & 0.08 & 0.52 & 0.00 \\
\hline $\mathrm{LL}$ & -70.87 & -79.76 & -72.81 & -73.68 & -59.56 \\
\hline LRT $\chi_{2}^{2}$ & 26.84 & 0.14 & 17.60 & 17.89 & 4.52 \\
\hline p-value & $<0.0001$ & 0.93 & 0.0002 & $<0.0001$ & 0.10 \\
\hline
\end{tabular}


645 Fig. 1: Detrended sediment core data for midge egg capsules and diatoxanthin, echinenone, 646 alloxanthin, $\beta$-carotene, and chlorophyll- $a$ (dots). Smoothing of midge (gray lines) and pigment

647 data (black lines) was performed to make fluctuating patterns in the data more clear; a direct form

648 II transposed filter was used with numerator coefficients $(0.25,0.5,0.25)$, and denominator

649 coefficient 1.

650

651 Fig. 2: Fit of the state-space model (Eqs. 2, 3) to detrended diatoxanthin (solid dots) and midge 652 egg capsule abundance (open dots). Solid and dashed black lines give the fit of the model to the 653 observed values $x^{*}(t)$ and $u^{*}(t)$ of diatoxanthin and midges (Eq. 3), whereas the solid and dashed 654 gray lines give the estimates of the deposition rates prior to sediment mixing (Eq. 2). 

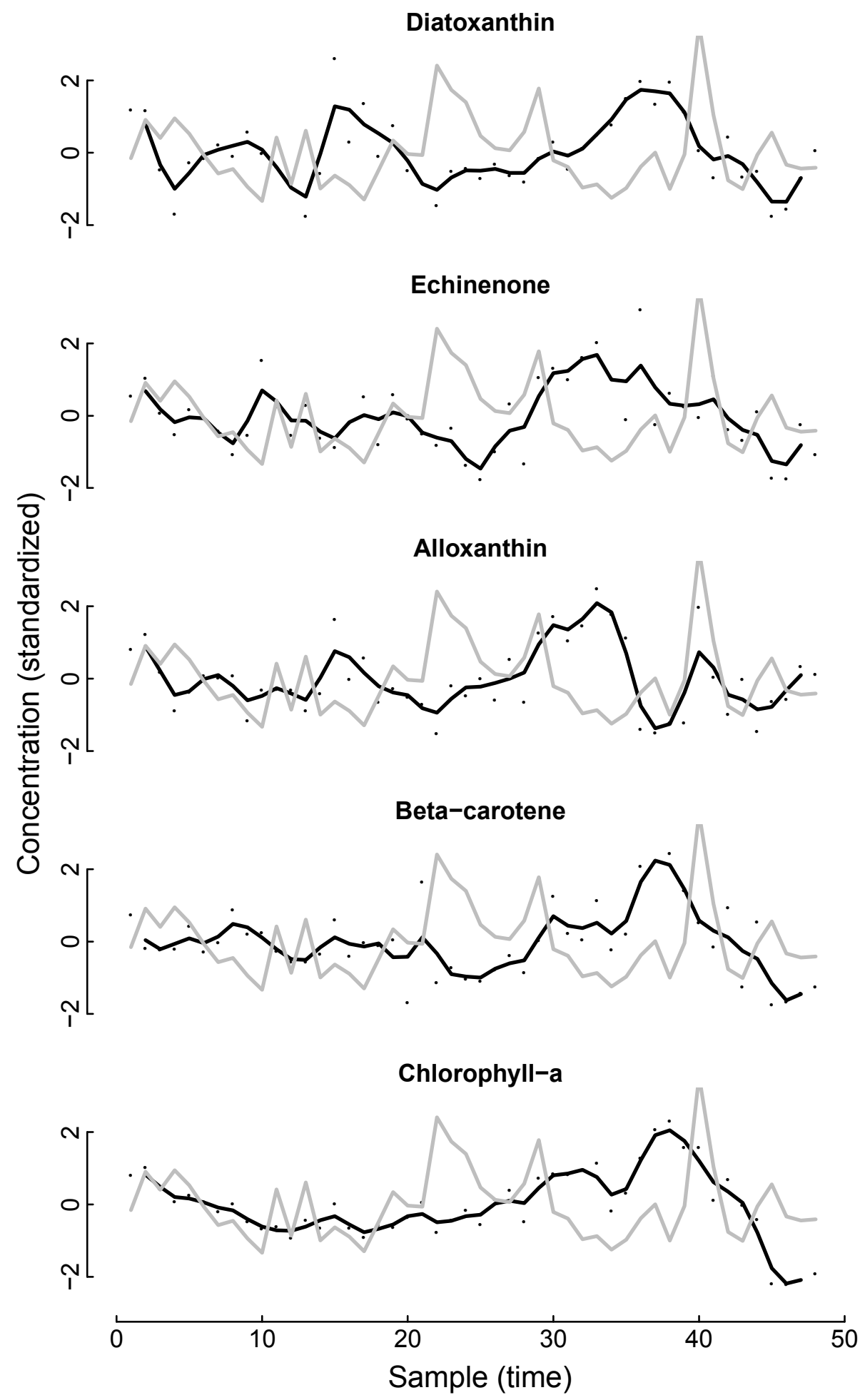


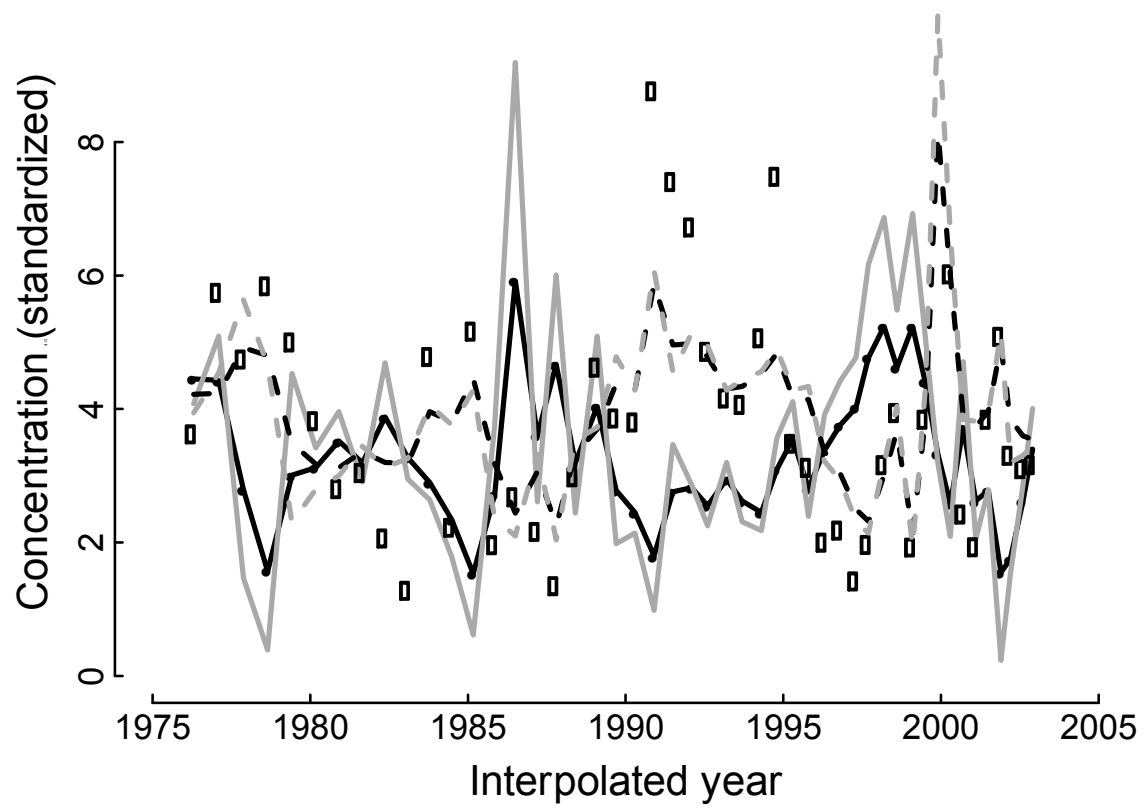

659 
